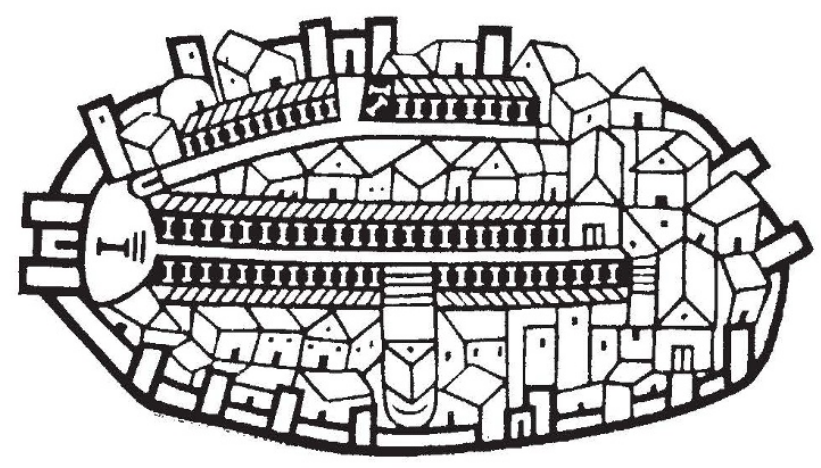

Jerusalem fragment of Medeba map of about AD 560.

and this imposing volume, originally published in a Hebrew edition, contains much of direct scientific interest. No country with a terrain as varied as that of Palestine and no people with an ancestry and history as rich as that of Israel can fail to command the attention at loast of geologists, archaeologists and sociologists, but botanists and zoologists too will find a fund of information far exceeding that available in a traditional Bible atlas. There is a map of the Mediterranean breeding areas and migration routes of the locust; another giving the distribution of plants on the verge of extinction-but no comment on the presence of lions in the Sephelah in the days of Samson.

For the ethnologist, Israel contains matorial for a thousand $\mathrm{PhD}$ theses, but among a welter of data on the settlement of the land during the past century and comparative demographic figures for the various population groups, only scant information is apparently available on the countries of origin of Jewish immigrants: there is simply a breakdown into two groups-those born in Europe, America or Australia, and those from Asia or Africa. On the other hand, the documentation of world Jewry is extensive and one is confronted with the fact that there are many Jews $(2.5$ million) in the Soviet Union as in Israel, and twice this number in the United States. (The world total is listed as $\mathbf{1 3 . 6}$ million for 1967.)

Having scanned through the remaining sections on local agriculture, industry, social services, culture and so on, most readers, and especially those interested in the history and religious significance of Israel, will want to go back to the collection of old maps-the Medeba map, for example, in a magnificent two-page spread. Archaeology is given meagre coverage, but thore are good historical maps from the times of the patriarchs up to the six-day war. (The standard map used throughout the book has the new de facto borders of June 1967.)

At 52 guineas, the book might have been graced with a rather more luxurious binding. Yet essentially this is not a prestige or presentation work, and those who will buy it will be readers likely to press it into hard service.

J. H. MORRIS

\section{STUDIES OF ORGANIZATIONS}

Organizational Analysis

A Sociological View. By Charles Perrow. (Behavioural Science in Industry Series.) Pp. xiii + 192. (Tavistock: London, August 1970.) $30 s$.

THIs book contains one basic idea about the study of organizations, many interesting case studies and even more argumentative and, in my view, superficial statements about the division of labour in the social sciences.

The basic idea is good, simple and constructive: "organizations differ in their tasks, and thus in the way they are run" (p. 49); "once this is realized, it becomes possible selectively to utilize the many techniques offered for solving organizational problems" (p. 91). In elaboration of this apparent truism Professor Perrow suggests a typology of organizations based on their technology and predicts organizational trouble if there exists a mismatch between technology and structure on the one hand, and control mechanisms or personnel policy on the other. In the development of these ideas the author presents a spirited defence of bureaucracy once technological problems are solved, for "no alternative way has been found to cope with the problem of organizing large numbers of people to produce goods and services efficiently" (p. 90).

This basic idea is, of course, not new and has been applied in this country by the Tavistock group in what they call socio-technical system analysis (which receives a somewhat condescending acknowledgment) and by Joan Woodward's studies which are fully and adequately reported. Still, a good idea gains from repetition and elaboration, particularly when presented in a readable, if somewhat breezy, style, as in the case here.

The book's most distinctive flavour stems from the skilful use of case studies when discussing the environmental context within which organizations function and their diverse organizational goals. Some of the material comes from Fortune magazine which publishes regularly profiles of business organizations, but non-profit organizations are also included (hospitals, charities, and the like) to support the interesting conclusion that business apparently suspends competition by legal and extralegal means more often than one would expect, whereas non-profit organizations engage in more competition than a naïve observer might anticipate.

The book is marred by a sociological imperialismstructure is "in", psychology is "out"-which cannot, of course, be maintained consistently. Not only does the foreword by Professor Vroom advocate an interdisciplinary approach, whereas the author's first paragraph claims the supremacy of sociology, the author himself is forced to inconsistencies, particularly in the interpretation of case studies where individual attitude and behaviour seem to count for more than his general stance would permit. The resistance to unorthodox labour-saving devices-Skinner pigeons as quality inspectors of pills cannot be understood in structural terms, and he does not even try to do so. Whether the study of industrial organizations should begin or end with the study of the behaviour and attitudes to work of individuals is a debatable point; to exclude it from investigation is surely not possible.

MARIE JAHODA

\section{STRESSES OF DAILY LIFE}

\section{Environment and Human Efficiency}

By E. C. Poulton. (A Monograph in the Bannerstone Division of American Lectures in Living Chemistry.) Pp. xxi+328. (Thomas: Springfield, Illinois, April 1970.) $\$ 15.50$.

THe purpose of this book is to summarize the knowledge that has emerged from experiments on human performance as affected by particular stressors. Each stressor is given only about ten pages so there is space to cover a large range including isolation, sleep disturbance, heat, cold, compression, vibration, noise, radiation and drugs.

The treatment is intended to be clear and unequivocal; each chapter begins with a summary and ends with some recipes on how to predict, reduce or avoid the effects noticed. Unfortunately, the state of the art is such that being unequivocal about human behaviour usually means being trite. For example, "radiant heat can produce burns. So also can contact with hot material" (p. 143), "decompression increases with height" 